\title{
Mechanical Properties of High Volume Fly Ash Concrete Reinforced with Hybrid Fibers
}

\author{
Rooban Chakravarthy, Srikanth Venkatesan, and Indubhushan Patnaikuni
}

School of Engineering, RMIT University, Melbourne, VIC, Australia

Correspondence should be addressed to Srikanth Venkatesan; srikanth.venkatesan@rmit.edu.au

Received 19 June 2016; Revised 10 October 2016; Accepted 9 November 2016

Academic Editor: Kazunori Fujikake

Copyright ( 2016 Rooban Chakravarthy et al. This is an open access article distributed under the Creative Commons Attribution License, which permits unrestricted use, distribution, and reproduction in any medium, provided the original work is properly cited.

Fly ash substitution to cement is a well-recognized approach to reduce $\mathrm{CO}_{2}$ emissions. Although fly ash concrete is prone to brittle behavior, researchers have shown that addition of fibers could reduce brittle behavior. Previous research efforts seem to have utlised a single type of fiber or two types of fibers. In this research, three types of fibers, steel, polypropylene, and basalt as $0 \%, 0.50 \%, 0.75 \%$, and $1 \%$ by volume of concrete, were mixed in varying proportions with concrete specimens substituted with $50 \%$ fly ash (class $\mathrm{F}$ ). All specimens were tested for compressive strength, indirect tensile strength, and flexural strength over a period of 3 to 56 days of curing. Test results showed that significant improvement in mechanical properties could be obtained by a particular hybrid fiber reinforcement combination ( $1 \%$ steel fiber, $0.75 \%$ polypropylene fiber, and $0.75 \%$ basalt fiber). The strength values were observed to exceed previous research results. Workability of concrete was affected when the fiber combination exceeded 3\%. Thus a limiting value for adding fibers and the combination to achieve maximum strengths have been identified in this research.

\section{Background}

Fly ash is generally an industrial waste obtained from burning coal. Fly ash substitution to cement is a well-recognized approach to reduce $\mathrm{CO}_{2}$ emissions. Malhotra [1] observed significant improvement in strength and durability with the substitution of high volume class F fly ash in ordinary Portland cement (OPC). Concrete in general and fly ash concrete in particular with $50 \%$ or more high volume replacements can experience brittle behavior. Under these circumstances, researchers have trialed the addition of fiber reinforcements to concrete. Thomas [2] observed that the addition of fibers led to improved stiffness of concrete or holding the matrix together after crack initiation or a combination of both mechanisms. Fiber reinforced cement composites were also observed to gain much higher strength for increasing strain rates in comparison to normal concrete [3,4]. Reference [5] observed that the function of fibers as secondary reinforcement in concrete inhibited crack initiation and propagation and improved the mechanical properties of concrete such as compressive strength, tensile strength, flexural strength, impact resistance, and toughness. In the case of Hannant [6], the addition of fibers provided better performance for the concrete while the addition of fly ash provided better workability and strength gain. The above references provide evidence to support the combinations of fly ash concrete with fiber reinforcements to enhance the mechanical properties. Some of these works specific to different types of fibers are noted below.

In the literature, three types of fibers that were added to fly ash concrete are widely discussed: steel, polypropylene, and basalt. With the addition of steel fibers concrete toughness was observed to be proportional to fiber content in both static and dynamic loading conditions as shown by Zollo [7] and Yet et al. [8]. Further, improvements in strain rates leading to enhanced strength were also noted. Steel fiber was observed to provide better bond strength and enhanced pullout resistance [9]. The equivalent bond strength of straight steel fibers, which are commonly used in ultrahigh performance fiber reinforced concrete, was doubled by optimizing the ultrahigh performance concrete matrix through composition and particle size distribution. This led to typical pullout load slip hardening behavior that is desirable for high tensile strength, high energy absorbing, and strain hardening of 
concrete [9]. Therefore it can be seen that the addition of steel fibers has the ability to bond well with concrete and can provide better pullout resistance.

Addition of polypropylene fiber was found to improve the durability of concrete composites containing fly ash and silica fume but showed adverse effect on the workability of concrete. In addition, water permeability, dry shrinkage strain, and the depth of carbonation of concrete decreased gradually with the increase of fiber volume fraction [11]. However Yao et al. [12] observed that at constant volume fraction $(0.5 \%)$ of hybrid fibers, the addition of polypropylene fibers to carbon and steel fibers provided varied results. Notwithstanding these limitations, as a member of polymer fibers, polypropylene fiber captivated the most recognition among researchers because of its enhanced shrinkage cracking resistance, low cost, and its excellent toughness in the concrete $[13-16,19]$. Polypropylene fibers were observed to improve the failure impact resistance of concrete with little statistical influence on the compressive or flexural strength of concrete. Flexural toughness and impact resistance showed an increase in the presence of polypropylene fibers in the concrete [14, 17]. A large number of polypropylene fibers distributed uniformly in the concrete composite resulted in decreased bleeding and segregation of the fresh concrete mixture due to the formation of grid like structures [18].

The addition of basalt fiber was observed to improve the deformation and energy absorption properties without notable enhancement in dynamic compressive strength [19]. Addition of basalt fibers up to $2 \%$ of concrete volume together with mineral admixtures improved the compressive strength and the improvement in strains corresponded to maximum compressive strength [20]. The basalt fiber significantly improved the tensile strength, flexural strength, and toughness index, whereas the compressive strength showed no obvious increase [21]. The degradation of basalt fiber in concrete changed into small parts different from their original form [22], thus strengthening the mix overall. Steel fibers were observed as a better strengthening material in high volume fly ash concrete but the addition of basalt fiber in combination resulted in decreased compressive strength. However the fracture energy and flexural strength improved with the addition of basalt fiber. As the basalt fiber content increased, concrete showed higher ultimate loads, larger deflections before failure that resulted in higher fracture energy values [23].

From the above review, it can be noted that steel fiber (high modulus fiber) is stronger and stiffer which improves the concrete strength, while polypropylene fiber (low modulus fiber) has the capacity to strengthen brittle cementitious materials and is more flexible and has the property to retain heat for a prolonged time which leads to improved toughness and strain capacity in the postcracking section and retard early cracks. Basalt fiber which is high in oxidation resistance and radiation resistance, fracture energy, and abrasion resistance leads to increase in the flexural strength.

In summary, various researchers have used steel, polypropylene, and basalt fibers mostly as individual additions and rarely as combinations to improve the properties of concrete. Therefore, it is logical to postulate that the combination of fibers may provide reasonable improvements overall and negate some of the disadvantages noted in the literature. This postulation requires an experimental investigation. Further sections of this paper present the experimental program and test results arising from the combination of fibers (steel, polypropylene, and basalt) in hybrid form added to high volume fly ash concrete.

\section{Experimental Program}

2.1. Materials. Following materials were used in the experimental program: cement, Type I Portland Cement with specific gravity $=3.14$; fine aggregate, river sand that passed through $4.75 \mathrm{~mm}$ sieve; and coarse aggregate, granite stone that passed through $12.5 \mathrm{~mm}$ IS sieve and retained on $10 \mathrm{~mm}$ sieve. Fly ash procured from the Tarong Power Plant was used and it was tested in the concrete laboratory at RMIT University and the results are presented in Appendix (Table 2). The steel fiber of length $40 \mathrm{~mm}$ and diameter $0.3 \mathrm{~mm}$, polypropylene fiber of length $15 \mathrm{~mm}$ with diameter $100 \mu \mathrm{m}$, and basalt fiber of length $12 \mathrm{~mm}$ with diameter $20 \mu \mathrm{m}$ were used in this experimental investigation. The water reducing admixture, naphthalene formaldehyde sulfonate (Sikament), was used in all mixing in the experimental work. Lime powder was used to improve the presence of alkali in fly ash. Normal tap water was used for mixing the concrete throughout the experimental work. It was ensured that all of these materials complied with respective material standards or properties.

2.2. Specimen Mix Details. Control specimen is $50 \%$ cement and $50 \%$ class $\mathrm{F}$ fly ash with no fibers. Although the percentage of fly ash mix is dependent on a number of factors, there is sufficient agreement in the literature that brittle behavior is dominant once the fly ash percentage crosses $50 \%$. The authors have used 50\%-50\% mix in our previous endeavors [24]. Variations of steel fiber are $0.5 \%$ and $1 \%$, polypropylene at $0.5 \%$ and $0.75 \%$, and basalt at $0.5 \%, 0.75 \%$, and $1 \%$ consistent with the literature noted in the previous section. Although these combinations are selected based on previous research studies a proper combination of basalt fibers does not seem to exist. As the basalt fiber dissolves into the mix, it was decided to include only three ranges into the mixing regime. These mix details are presented in Table 1.

Cylindrical specimens were cast with dimensions of $100 \mathrm{~mm}$ diameter $\times 200 \mathrm{~mm}$ length for compressive strength test, cylindrical specimens with dimensions of $150 \mathrm{~mm}$ diameter $\times 300 \mathrm{~mm}$ length for indirect tensile strength test, and beam specimens with dimensions of $350 \mathrm{~mm} \times 100 \mathrm{~mm} \times$ $100 \mathrm{~mm}$ for flexural strength test. The numbers of specimens used for this research are

(i) compressive strength tests, 270 cylinders;

(ii) indirect tensile strength tests, 54 cylinders;

(iii) flexure strength tests, 54 beams.

Methodology for concrete mixing involved the following:

(1) Aggregates and sand were washed with water and completely dried. Then both were placed in the concrete mixer and dry mixed for 2 minutes. 
TABLE 1: Specimen nomenclature.

\begin{tabular}{|c|c|c|c|c|c|c|}
\hline \multirow{2}{*}{ Sl. number } & \multirow{2}{*}{ Mix number } & \multicolumn{3}{|c|}{ Fibers } & \multirow{2}{*}{ Cement } & \multirow{2}{*}{ Class F fly ash } \\
\hline & & Steel fiber & Polypropylene fiber & Basalt fiber & & \\
\hline 1 & $\mathrm{C}$ & $0 \%$ & $0 \%$ & $0 \%$ & $50 \%$ & $50 \%$ \\
\hline 2 & S1 & $0.50 \%$ & $0 \%$ & $0 \%$ & $50 \%$ & $50 \%$ \\
\hline 3 & S2 & $1 \%$ & $0 \%$ & $0 \%$ & $50 \%$ & $50 \%$ \\
\hline 4 & P1 & $0 \%$ & $0.50 \%$ & $0 \%$ & $50 \%$ & $50 \%$ \\
\hline 5 & P2 & $0 \%$ & $0.75 \%$ & $0 \%$ & $50 \%$ & $50 \%$ \\
\hline 6 & $\mathrm{~B} 1$ & $0 \%$ & $0 \%$ & $0.50 \%$ & $50 \%$ & $50 \%$ \\
\hline 7 & $\mathrm{~B} 2$ & $0 \%$ & $0 \%$ & $0.75 \%$ & $50 \%$ & $50 \%$ \\
\hline 8 & B3 & $0 \%$ & $0 \%$ & $1 \%$ & $50 \%$ & $50 \%$ \\
\hline 9 & $\mathrm{X} 1$ & $0.50 \%$ & $0.50 \%$ & $0.50 \%$ & $50 \%$ & $50 \%$ \\
\hline 10 & $\mathrm{X} 2$ & $0.50 \%$ & $0.75 \%$ & $0 \%$ & $50 \%$ & $50 \%$ \\
\hline 11 & $\mathrm{X} 3$ & $0.50 \%$ & $0.75 \%$ & $0.75 \%$ & $50 \%$ & $50 \%$ \\
\hline 12 & $\mathrm{X} 4$ & $0.50 \%$ & $0 \%$ & $1 \%$ & $50 \%$ & $50 \%$ \\
\hline 13 & Y1 & $1 \%$ & $0.50 \%$ & $0.50 \%$ & $50 \%$ & $50 \%$ \\
\hline 14 & $\mathrm{Y} 2$ & $1 \%$ & $0.75 \%$ & $0 \%$ & $50 \%$ & $50 \%$ \\
\hline 15 & Y3 & $1 \%$ & $0.75 \%$ & $0.75 \%$ & $50 \%$ & $50 \%$ \\
\hline 16 & $\mathrm{Y} 4$ & $1 \%$ & $0 \%$ & $0.75 \%$ & $50 \%$ & $50 \%$ \\
\hline 17 & Y5 & $1 \%$ & $0 \%$ & $1 \%$ & $50 \%$ & $50 \%$ \\
\hline 18 & Y6 & $1 \%$ & $1 \%$ & $1 \%$ & $50 \%$ & $50 \%$ \\
\hline
\end{tabular}

TABLE 2: Chemical composition of fly ash.

\begin{tabular}{lcc}
\hline Characteristics & Tarong fly ash & ASTM class F fly ash \\
\hline $\mathrm{SiO}_{2}$ & 65.9 & The sum of $\mathrm{SiO}_{2}+\mathrm{Al}_{2} \mathrm{O}_{3}+$ \\
$\mathrm{Al}_{2} \mathrm{O}_{3}$ & 28.89 & $\mathrm{Fe}_{2} \mathrm{O}_{3}(\min 70 \%)$ \\
$\mathrm{Fe}_{2} \mathrm{O}_{3}$ & 0.38 & \\
\hline $\mathrm{TiO}_{2}$ & 1.97 & \\
$\mathrm{MnO}$ & 0 & \\
$\mathrm{MgO}$ & 0.15 & \\
$\mathrm{CaO}$ & 0.06 & \\
$\mathrm{Na}_{2} \mathrm{O}$ & 0.05 & \\
$\mathrm{~K}_{2} \mathrm{O}$ & 0.26 & \\
$\mathrm{P}_{2} \mathrm{O}_{5}$ & 0.08 & \\
$\mathrm{SO}_{3}$ & 0.03 & Max, 5\% \\
$\mathrm{LOI}$ & 1.24 & Max, 6\% \\
\hline
\end{tabular}

(2) Cement, fly ash, and lime powder (5\%) were added in the mixer with aggregates and sand and dry mixed for 2 minutes.

(3) Then fibers (steel fiber, polypropylene fiber, and basalt fiber) were added one after another and dry mixed for 1 minute. Then normal water $(85 \%)$ is added and mixed for approximately 2 minutes.

(4) Remaining mixing water (15\%) and plasticizer were added to the mixer and mixed for 3 minutes. Then the mixed concrete was cast into the specimen moulds and vibrated simultaneously in the vibrator for 1 minute to remove any air remaining entrapped mainly to avoid voids. Each specimen was allowed to stand for 24 hours in concrete laboratory before demolding.

\subsection{Tests and Methods}

2.3.1. Compressive Strength Test (AS 1012.9). The compressive strength test was carried out in accordance with Australian Standard [25] using MTS machine with a loading capacity of $1000 \mathrm{kN}$ and a loading rate of $20 \pm 2 \mathrm{MPa} /$ minute. Three cylindrical specimens $(100 \mathrm{~mm}$ diameter $\times 200 \mathrm{~mm}$ length) were tested for compressive strength at the age of 3 days, 7 days, 14 days, 28 days, and 56 days after casting. The average results of the three cylindrical specimens are reported in this paper.

2.3.2. Indirect Tensile Strength (AS 1012.10). The Indirect tensile strength test was carried out in accordance with Australian Standard [26] using MTS machine with a loading capacity of $1000 \mathrm{kN}$ and a loading rate of $1 \pm 0.1 \mathrm{MPa} /$ minute provided with indirect tensile strength test equipment (for details of testing arrangement refer to [26]). Three cylindrical specimens ( $150 \mathrm{~mm}$ diameter $\times 300 \mathrm{~mm}$ length) were tested for flexural strength at the age of 28 days after casting. The average results of the three cylindrical specimens are reported.

The indirect tensile strength $(T)$ of the specimen was calculated using

$$
T=\frac{2000 P}{\pi L D}
$$

where $T$ is indirect tensile strength $(\mathrm{MPa}), P$ is maximum applied force indicated by the testing machine, $L$ is length $(\mathrm{mm})$, and $D$ is diameter $(\mathrm{mm})$. 
2.3.3. Flexural Strength Test: Four-Point Bending Test (AS 1012.11). The modulus of rupture development of concrete test was carried out in accordance with Australian Standard [27] using hydraulic MTS testing machine having a loading capacity of $1000 \mathrm{kN}$ (for details of testing arrangement refer to [26]). Three beam specimens were tested for flexural strength until the maximum load is reached after 28 days of casting. The average results of the three beam specimens are reported.

The modulus of rupture $\left(f_{c f}\right)$ of the specimen was calculated using

$$
f_{c f}=\frac{P L(1000)}{B D^{2}}
$$

where $f_{c f}$ is modulus of rupture $(\mathrm{MPa}), P$ is maximum applied force indicated by testing machine $(\mathrm{kN}), L$ is span length $(\mathrm{mm}), B$ is average width of specimen at the section of failure $(\mathrm{mm})$, and $D$ is average depth of specimen at the section of failure ( $\mathrm{mm})$.

The modulus of rupture $\left(f_{c f}\right)$ is used to find the tensile strength of the concrete. The correlation between the modulus of concrete rupture and its tensile strength $\left(f_{c t}\right)$ based on Australian Standard [28] Article 3.1.1.3 (a) as follows:

$$
f_{c t}=0.6 f_{c f}
$$

where $f_{c t}$ is the uniaxial tensile strength $(\mathrm{MPa})$ and $f_{c f}$ is the modulus of rupture in accordance with AS 1012.11 (MPa).

\section{Results and Discussion}

3.1. Compressive Strength. As can be seen from Figures 1 and 2 , an increase in compressive strength between the control mix and hybrid mixes is clearly evident. In particular it can be seen that at 7 days (Figure 1) some of the mixes appear to have low strengths more than X3, Y3, and Y5 while at around 28 days the strength values seem to stabilize owing to curing of concrete. An average increase of $30 \%$ in compressive strength of fiber specimens over control concrete is observed at 28 days with a peak value of $75 \%$ increase for specimen Y3 (1\% steel, $0.75 \%$ polypropylene, and $0.75 \%$ basalt). At 56 days no significant differences in strengths were observed to 28 -day strengths, suggesting that 28-day comparisons are reliable for further discussion.

As Y3 mix is observed to have the greatest strength from Figure 2, a comparison of $\mathrm{Y} 3 \mathrm{mix}$ and control mix with results of OPC obtained by Çolak [10] is presented in Figure 3. This comparison clearly shows that the control mix has lower strength values than the OPC which might be due to the presence of fly ash while the Y3 mix has increased compressive strength more than both the OPC and the control mix. We also note there are other mixes such as Y5 that have greater strength than OPC. In general, it can be noted that fiber mix concrete can ensure higher compressive strength than normal OPC.

3.2. Indirect Tensile Strength. Figure 4 presents the comparison of indirect tensile strength test results of all mixes at 3 days, 7 days, 14 days, 28 days, and 56 days. There is a random strength increase throughout the duration of observation.

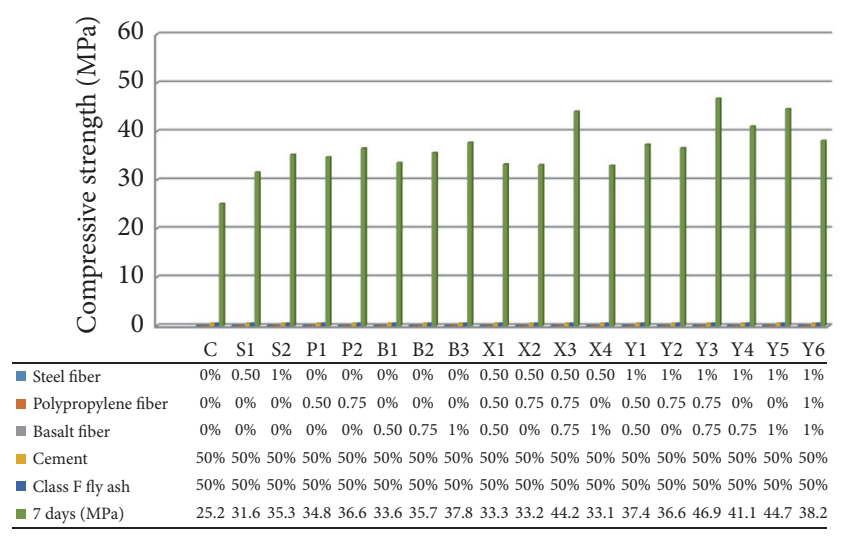

FIgURE 1: Comparison of compressive strength between control concrete ( $50 \%$ cement, $50 \%$ fly ash, and no fibers) and hybrid fiber mixes at 7 days.

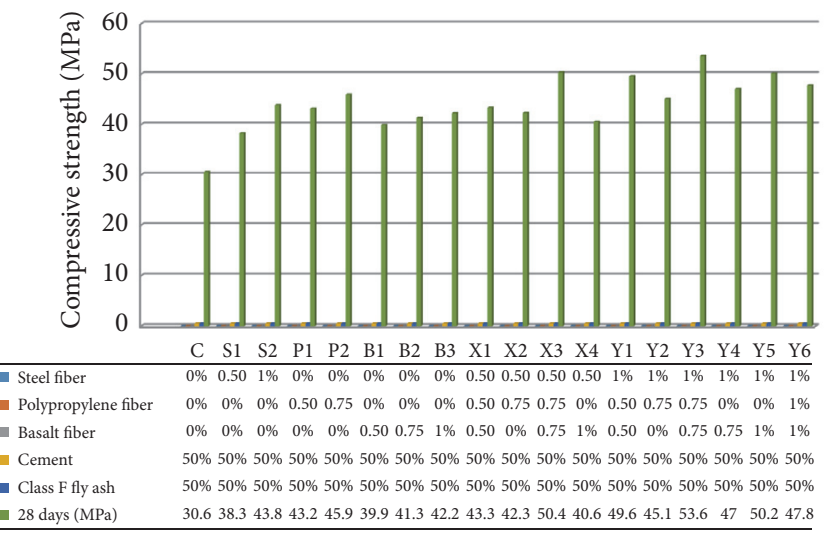

FIGURE 2: Comparison of compressive strength between control concrete (50\% cement, $50 \%$ fly ash, and no fibers) and hybrid fiber mixes at 28 days.

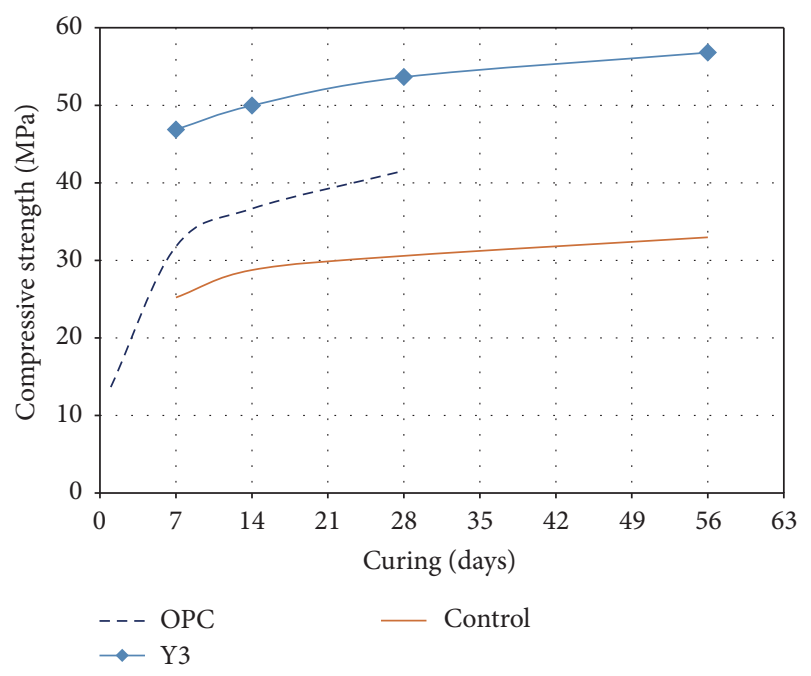

FIgURE 3: Comparison of compressive strength for hybrid fiber mix $\mathrm{Y} 3$ and control mix with compressive strength of OPC from Colak [10]. 


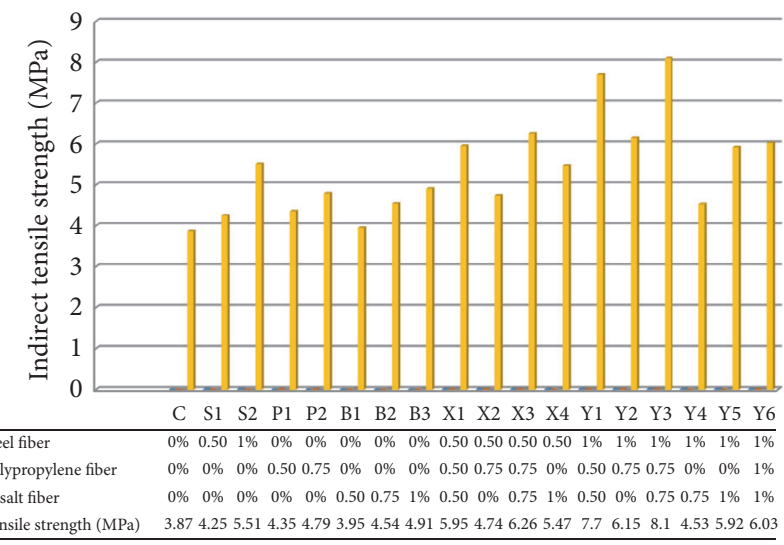

FIGURE 4: Comparison of indirect tensile strength for hybrid fibers at 28 days.

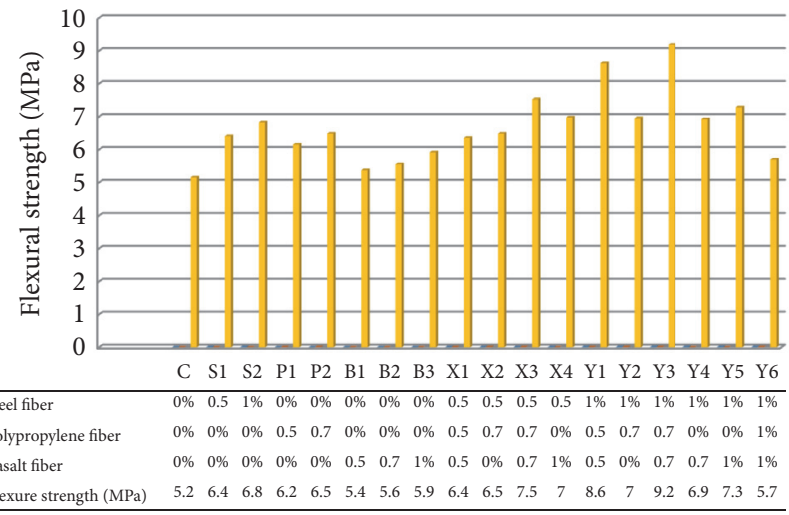

FIGURE 5: Comparison of flexural strength for hybrid fiber mixes at 28 days.

Comparing indirect tensile strength test results, Y1 (1\% steel fiber, $0.5 \%$ polypropylene fiber, and $0.5 \%$ basalt fiber) and Y3 (1\% steel fiber, $0.75 \%$ polypropylene fiber, and $0.75 \%$ basalt fiber) in hybrid form give higher tensile strength when compared to control concrete and individual fibers.

3.3. Flexural Strength from Four-Point Bending Tests. Figure 5 presents the comparison of flexural strength test results at 3 days, 7 days, 14 days, 28 days, and 56 days. Slight increase in strengths can be observed throughout the duration of observation. Comparing flexural strength test results, Y1 (1\% steel fiber, $0.5 \%$ polypropylene fiber, and $0.5 \%$ basalt fiber) and Y3 (1\% steel fiber, $0.75 \%$ polypropylene fiber, and $0.75 \%$ basalt fiber) in hybrid form give maximum flexural strength when compared to control concrete, individual fiber reinforced high volume fly ash concrete, and other hybrid mix.

Clearly the above figures have shown that the mix Y3 has significantly higher values across the testing regime. Brief investigations of the contribution of different mix proportions to the three strengths were analysed using strength values obtained at 28 days. First, the contribution of individual fibers is presented in Figure 6. It is interesting to

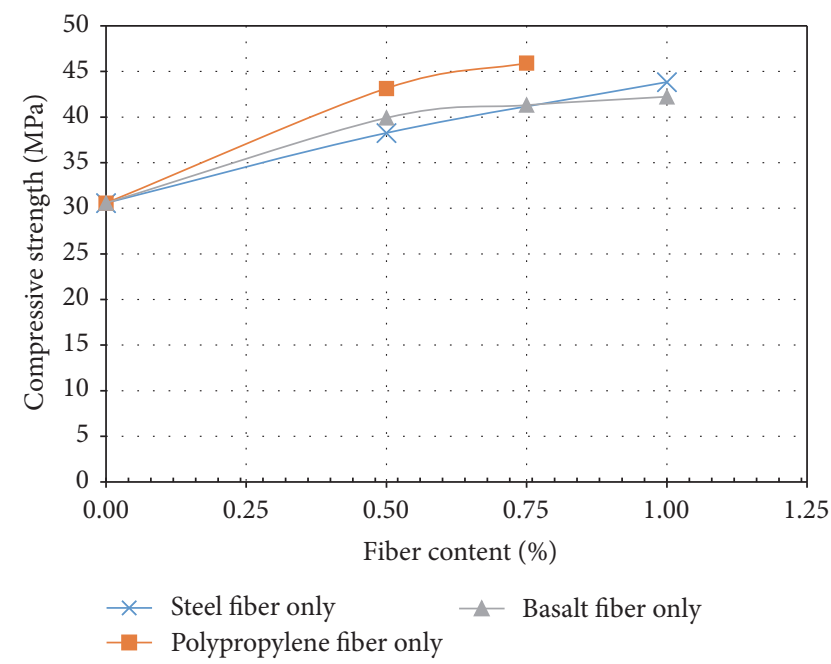

FIGURE 6: Comparison of compressive strengths in individual fiber mix.

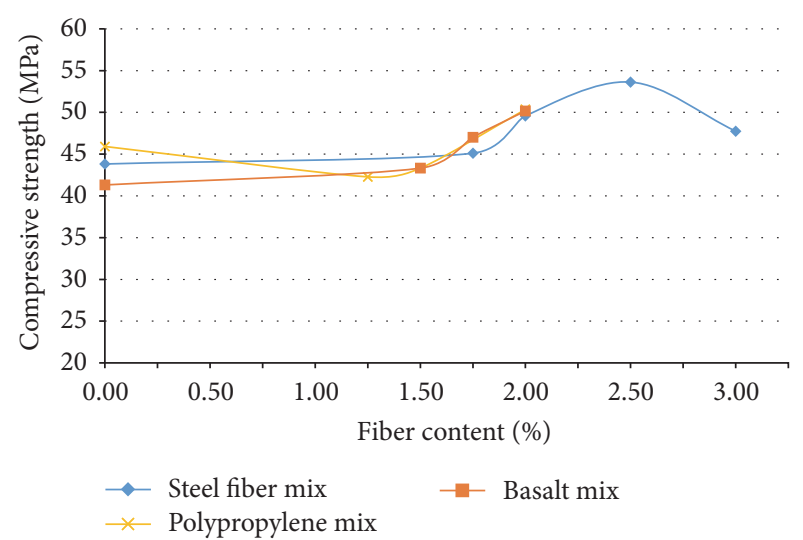

FIgURE 7: Comparison of compressive strengths with fiber mix at different proportions.

note that polypropylene fiber provides higher initial strengths although it starts to flatten out around $0.75 \%$. A similar but low level of strength is observed for basalt fiber. However the trend line for steel is linear up to $1 \%$. This observation suggests that an increase in steel fiber may be desirable although the use of basalt and polypropylene fibers beyond $0.75 \%$ may not be necessary. This observation from Figure 6 is quite interesting as the results show a higher strength value for the Y3 mix (i.e., $1 \%$ steel, $0.75 \%$ polypropylene, and $0.75 \%$ basalt). We also observed the workability of concrete to be affected when the combined percentage exceeded 3\%.

A comparison of compressive strengths with hybrid combination is presented in Figure 7. It can be seen that hybrid combinations up to $1.75 \%$ lead to similar strengths but the noticeable jump is observed only at Y3 combination (a total of $2.5 \%$ with $1 \%$ steel and polypropylene and basalt at $0.75 \%)$ and when all the three mixed at $3 \%$ the values drop down significantly. 

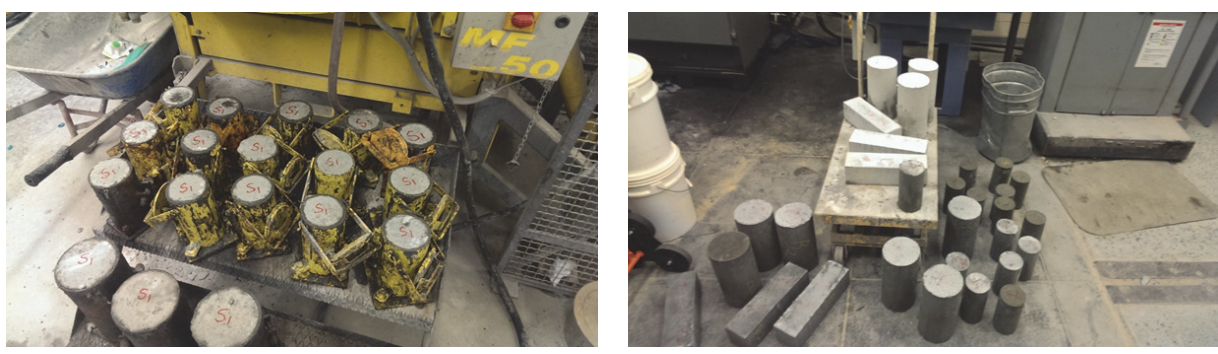

FIGURE 8: Specimens cast and ready for testing.

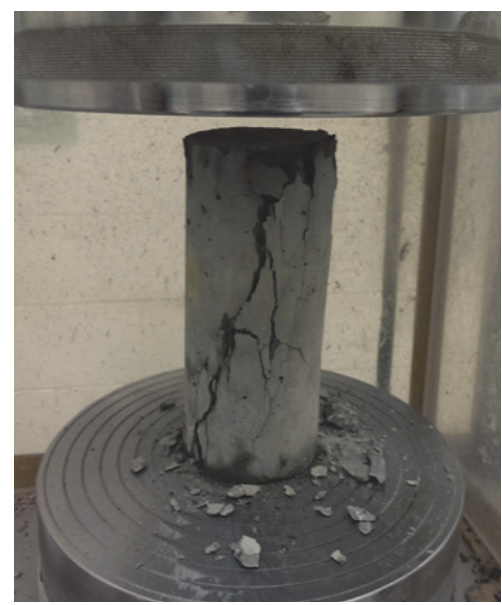

(a)

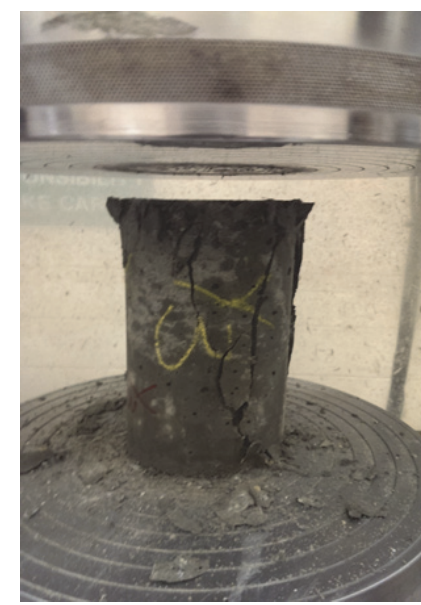

(b)

FIGURE 9: Crack patterns at ultimate failure load: control specimen (a) and specimen (Y3) (b). Reduced cracks in Y3 specimen.

\section{Concluding Remarks}

This paper has shown that three fibers (steel, polypropylene, and basalt) can be added in a hybrid combination to achieve compressive strengths higher than the normal OPC. In particular, a hybrid combination of $1 \%$ steel, $0.75 \%$ polypropylene, and $0.75 \%$ basalt provided the highest strength results in terms of common mechanical properties. The paper has also shown that significant increase in flexural strength and tensile strengths can be observed simultaneously leading to the suggestion that some of the negative effects of individual fiber additions can be avoided using the hybrid fiber combination. A limiting combination of $3 \%$ overall has also been determined based on the workability of concrete. Further work may include the analysis of specimens in terms of matrix formulations, cracking behavior, and concrete toughness.

\section{Appendix}

See Table 2. For photos of specimens see Figures 8 and 9.

\section{Competing Interests}

The authors declare that there is no conflict of interests regarding the publication of the paper.

\section{References}

[1] V. M. Malhotra, "Durability of concrete incorporating highvolume of low-calcium (ASTM Class F) fly ash," Cement and Concrete Composites, vol. 12, no. 4, pp. 271-277, 1990.

[2] J. A. G. Thomas, "Fibre composites as construction materials," Composites, vol. 3, no. 2, pp. 62-64, 1972.

[3] A. E. Naaman and V. S. Gopalaratnam, "Impact properties of steel fibre reinforced concrete in bending," International Journal of Cement Composites and Lightweight Concrete, vol. 5, no. 4, pp. 225-233, 1983.

[4] M. Maalej, S. T. Quek, and J. Zhang, "Behavior of hybridfiber engineered cementitious composites subjected to dynamic tensile loading and projectile impact," Journal of Materials in Civil Engineering, vol. 17, no. 2, pp. 143-152, 2005.

[5] X. Luo, W. Sun, and S. Y. N. Chan, "Characteristics of highperformance steel fiber-reinforced concrete subject to high velocity impact," Cement and Concrete Research, vol. 30, no. 6, pp. 907-914, 2000.

[6] D. J. Hannant, "Durability of polypropylene fibers in Portland cement-based composites: eighteen years of data," Cement and Concrete Research, vol. 28, no. 12, pp. 1809-1817, 1998.

[7] R. F. Zollo, "Fiber-reinforced concrete: an overview after 30 years of development," Cement and Concrete Composites, vol. 19, no. 2, pp. 107-122, 1997.

[8] T. C. Yet, R. Hamid, and M. Kasmuri, "Dynamic stress-strain behaviour of steel fiber reinforced high-performance concrete 
with fly ash," Advances in Civil Engineering, vol. 2012, Article ID 907431, 6 pages, 2012.

[9] P. Zhang and Q.-F. Li, "Effect of polypropylene fiber on durability of concrete composite containing fly ash and silica fume," Composites Part B: Engineering, vol. 45, no. 1, pp. 1587-1594, 2013.

[10] A. Çolak, "A new model for the estimation of compressive strength of Portland cement concrete," Cement and Concrete Research, vol. 36, no. 7, pp. 1409-1413, 2006.

[11] C. X. Qian and P. Stroeven, "Development of hybrid polypropylene-steel fibre-reinforced concrete," Cement and Concrete Research, vol. 30, no. 1, pp. 63-69, 2000.

[12] W. Yao, J. Li, and K. Wu, "Mechanical properties of hybrid fiberreinforced concrete at low fiber volume fraction," Cement and Concrete Research, vol. 33, no. 1, pp. 27-30, 2003.

[13] N. Banthia and R. Gupta, "Influence of polypropylene fiber geometry on plastic shrinkage cracking in concrete," Cement and Concrete Research, vol. 36, no. 7, pp. 1263-1267, 2006.

[14] A. M. Alhozaimy, P. Soroushian, and F. Mirza, "Mechanical properties of polypropylene fiber reinforced concrete and the effects of pozzolanic materials," Cement \& Concrete Composites, vol. 18, no. 2, pp. 85-92, 1996.

[15] H. A. Toutanji, "Properties of polypropylene fiber reinforced silica fume expansive-cement concrete," Construction and Building Materials, vol. 13, no. 4, pp. 171-177, 1999.

[16] K. Komloš, B. Babál, and T. Nürnbergerová, "Hybrid fibrereinforced concrete under repeated loading," Nuclear Engineering and Design, vol. 156, no. 1-2, pp. 195-200, 1995.

[17] R. Bagherzadeh, A.-H. Sadeghi, and M. Latifi, "Utilizing polypropylene fibers to improve physical and mechanical properties of concrete," Textile Research Journal, vol. 82, no. 1, pp. 88-96, 2012.

[18] O. Kayali, "Effect of high volume fly ash on mechanical properties of fiber reinforced concrete," Materials and Structures, vol. 37, no. 269, pp. 318-327, 2004.

[19] W. M. Li and J. Y. Xu, "Mechanical properties of basalt fiber reinforced geopolymeric concrete under impact loading," Materials Science and Engineering A, vol. 505, no. 1-2, pp. 178186, 2009.

[20] T. Ayub, N. Shafiq, and F. M. Nuruddin, "Mechanical properties of high-performance concrete reinforced with basalt fibers," Procedia Engineering, vol. 77, pp. 131-139, 2014.

[21] C. H. Jiang, K. Fan, F. Wu, and D. Chen, "Experimental study on the mechanical properties and microstructure of chopped basalt fibre reinforced concrete," Materials \& Design, vol. 58, pp. 187-193, 2014.

[22] N. Kabay, "Abrasion resistance and fracture energy of concretes with basalt fiber," Construction and Building Materials, vol. 50, pp. 95-101, 2014.

[23] J. Sim, C. Park, and D. Y. Moon, "Characteristics of basalt fiber as a strengthening material for concrete structures," Composites Part B: Engineering, vol. 36, no. 6-7, pp. 504-512, 2005.

[24] M. Solikin, S. Setunge, and I. Patnaikuni, "Experimental design analysis of ultra fine flyash, lime water, and basalt fiber in mix proportion of high volume flyash concrete," in Proceedings of the 3rd CUTSE International Conference, Sarawak, Malaysia, November 2013.

[25] AS 1012.9, Method 9: Determination of the Compressive Strength of Concrete Specimens, Australian Standard Comittee, Strathfield, Australia, 1999.
[26] AS 1012.10, Methods of Testing Concrete. Method 10: Determination of Indirect Tensile Strength of Conrete Cylinders ("Brazil" or Splitting Test), Australian Standard Association, Sydney, Australia, 2000.

[27] AS 1012.11, Method 11: Determination of the Modulus of Rupture, Australian Standard Committee, Strathfield, Australia, 2000.

[28] AS 3600, Concrete Structures, Standards Australia, Sydney, Australia, 2009. 

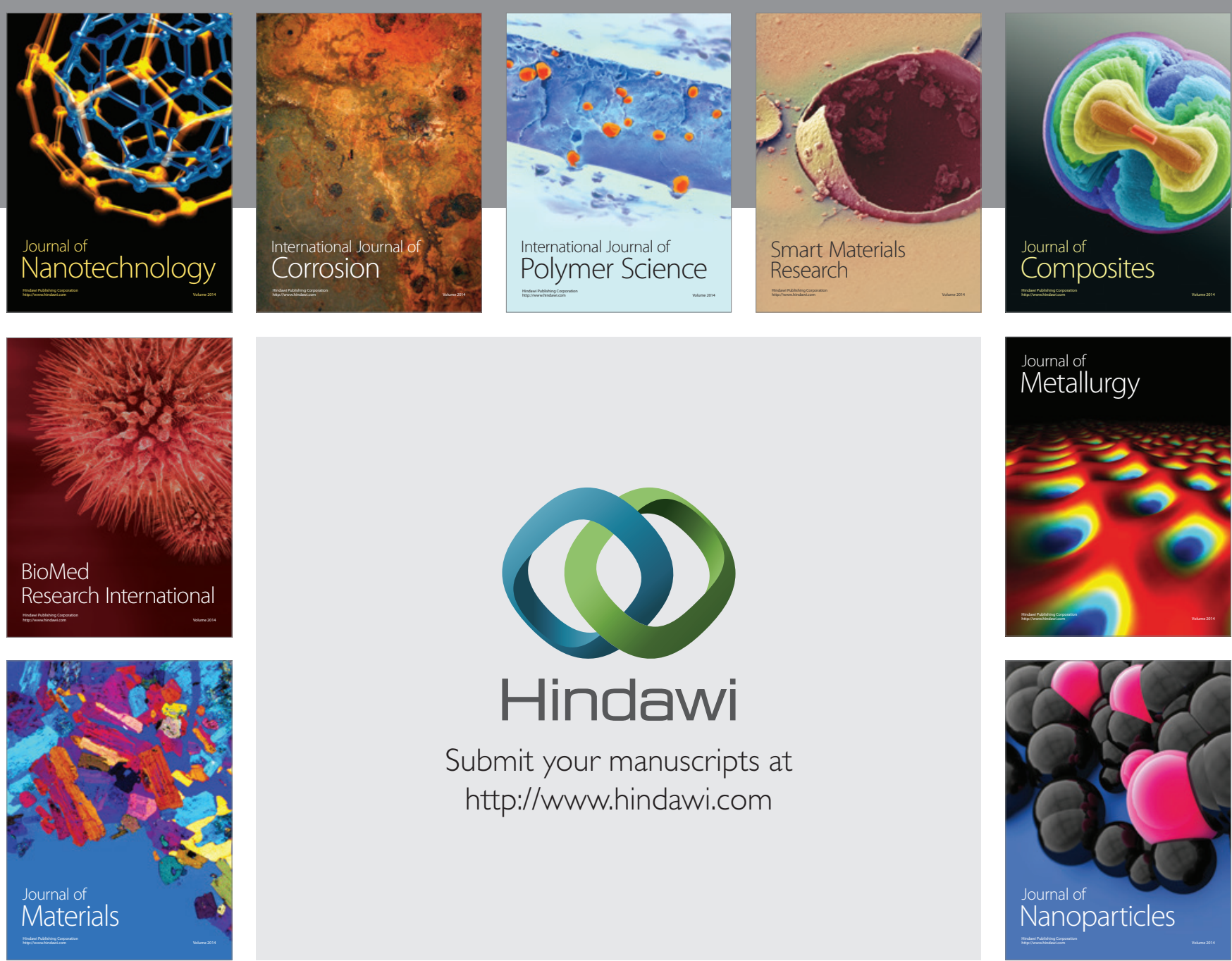

\section{Hindawi}

Submit your manuscripts at

http://www.hindawi.com

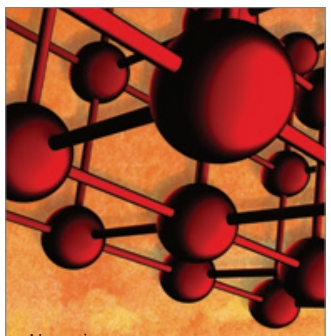

Materials Science and Engineering
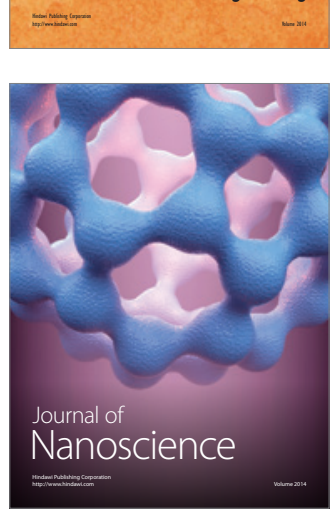
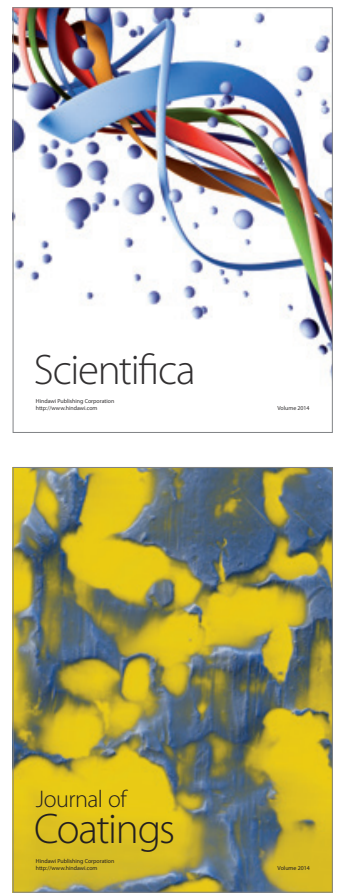
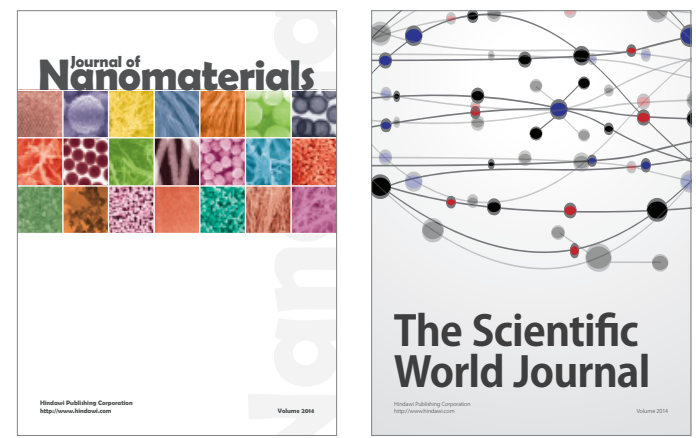

The Scientific World Journal
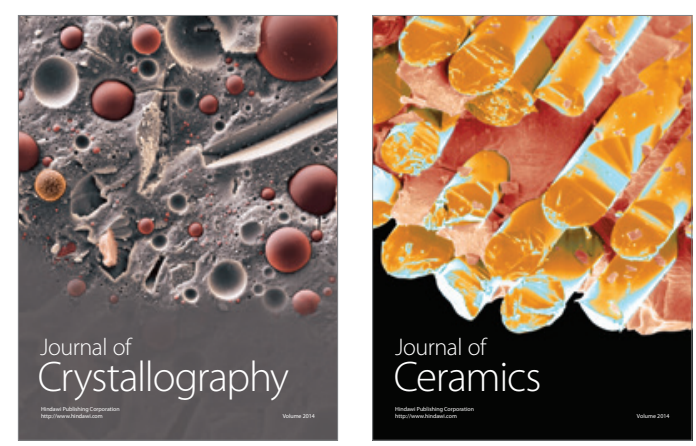
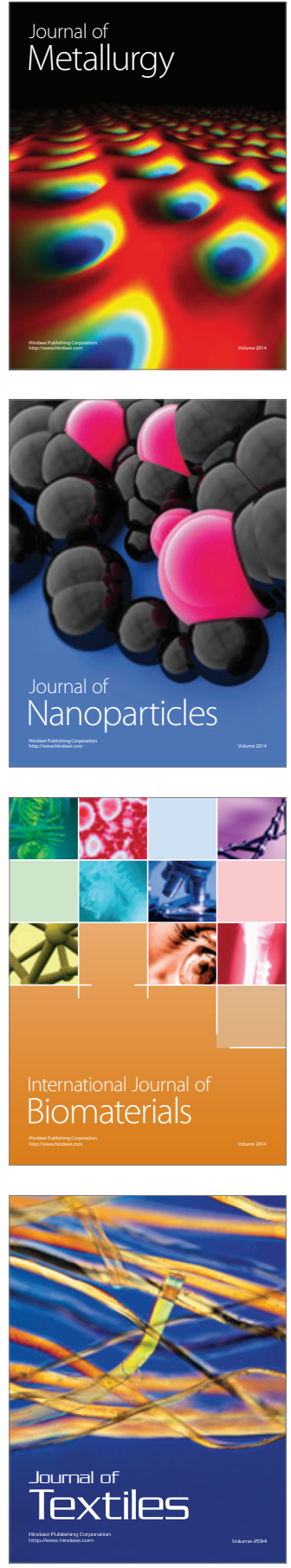